\title{
Research on Physical Training Methods Related To the Use of Weapons by the Police
}

\author{
Zhao Hua-Sun' (iD $\quad{ }^{1}$ Instructors, department of police training, Liaoning \\ police academy, Liaoning province, China
}

\begin{abstract}
The use of weapons is the most advanced form of force for police to stop the crime, but also an important embodiment of the authority of the police law enforcement. Over the years, the using of firearms for police in the physical training has been based on the training method of the shooting sports team, it is just focus on firing accuracy and ignoring the police professional characteristics, which cause certain effect to police in the critical moment when police use weapons. This article starting from the characteristics of the police profession, according to the working characteristics of the current status of China's police, put forward physical training methods relate with the police use weapons. It is a reference for the establishment of the physical training system for the use of weapon based on the characteristics of police professional and helping the majority of police improving the weapons use ability.
\end{abstract}

Keywords: Police, weapon, Using, Physical fitness, Training method, Researching.

\section{Contents}

1. Introduction

3. Endurance Training

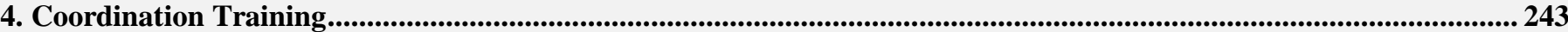

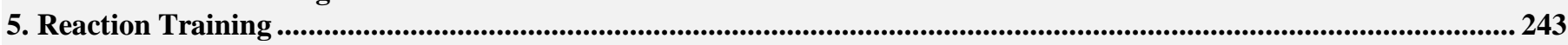

6. Conclusion.

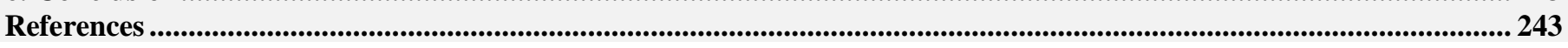

Citation | Zhao Hua-Sun (2016). Research on Physical Training Methods Related To the Use of Weapons by the Police. Asian Journal of Social Sciences and Management Studies, 3(4): 241-243.

\section{DOI:}

$\operatorname{ISSN}(\mathbf{E})$ :

$\operatorname{ISSN}(\mathbf{P})$ :

Licensed:

Funding:

Competing Interests:

Transparency:

Ethical:
History:

Publisher: 10.20448/journal.500/2016.3.4/500.4.241.243

2313-7401

2518-0096

This work is licensed under a Creative Commons Attribution 3.0 License $(\mathrm{cc}) \mathbf{E Y}$

This study received no specific financial support.

The author declares that there are no conflicts of interests regarding the publication of this paper.

The author confirms that the manuscript is an honest, accurate, and transparent account of the study was reported; that no vital features of the study have been omitted; and that any discrepancies from the study as planned have been explained.

This study follows all ethical practices during writing.

Received: 6 June 2016/ Revised: 24 June 2016/ Accepted: 6 July 2016/ Published: 12 July 2016 Asian Online Journal Publishing Group 


\section{Introduction}

As we all know, shooting is one kind of sports. However, the research of shooting is mainly focused on the technical aspects, but ignoring the physical training. Although the shooting training teams in all levels are making a more in-depth study in the physical training in recent years, however, due to the late start, the theoretical level and depth is not enough. The training of using weapons for police comes from the shooting of sports. For a long time, the using of weapons for the police training is also more concentrated in the technical level and there is little in depth of physical training. Therefore, the physical training of the use of weapons has not formed a systematic theoretical system, and it also affected the ability to use weapons for police in the process of the actual enforcement seriously. In addition, through the study we found that: the police use of weapons and shooting game project has a big difference. The shooting competition project has a high requirement for the stability of the static state and the ability of muscle control In addition, the training of the physical training of the aerobic for the shooting athletes can enable the shooter to keep the mind awake and quick-witted in a long time, and make the shooting sports reflect the best status and achievements (Guo, 2015). The police using of weapons is different from the shooting movement. Due to the characteristics of the profession, most of the time the police use the weapon is in the extremely urgent situation, the body has carried on the larger load movement or the psychological load is great. The method and purpose of the using of weapons and the results have a huge difference with the shooting project. Therefore, the use of weapons related to the police physical training can not be completely based on the physical training of the shooting program; it must meet the professional characteristics of the police. In view of this situation, the police use of weapons related physical training should include the following aspects.

\section{Strength Training}

Police in the process of law enforcement Whether it is shot in a static state or in a moving state Or a still shot after a heavy load they all Need the arm, waist and leg muscle strength. These forces are essential to keeping the firing stability. Therefore, in the exercise of strength training, we should focus on the upper limb, waist and leg muscle strength.

\subsection{Upper Limb Strength}

Upper limb is the combination position of people and the gun, but also is the position of a person to fight or is the main part of manual labor. Therefore, whether the upper limb strength is complete directly affect the effect of the use of weapons and even safety. If the upper limb strength is not enough, after a fight with the suspect, Lack of muscle strength of the upper limb will lead the gun instability, and even the gun was snatched away by others. in view of this situation, the police should be aware of the strengthening of upper limb strength exercise. If conditions permit, you can go to the gym for systematic training. If because the job is busy, no time to exercise, you can select push ups, dumbbell, and more common sports facilities in daily life, such as the horizontal bar, parallel bars, and other equipment upper body exercises.

\subsection{Waist Strength}

Waist is in the middle part of the human body and connecting the body's upper and lower limbs. Lack of strength of the waist will lead to the upper and lower extremity strength. Especially in the special geographical conditions, the body is in a state of distortion, there is no good waist strength will lead to the body is in an unstable state, and thus affect the effectiveness of the use of weapons. In view of this situation, no matter whether the police use the way of special physical training or the use of spare time for general training should look the waist training as the main content training. Generally speaking, the daily spare time, to sit up, drape leg lift and so on movement can effectively exercise the muscles of waist.

\subsection{Lower Limb Strength}

Lower limb combine the human body and the ground. The body must through the legs and ground combined to keep the body stable, and thus stable firing. In addition, when living in different terrain, the ups and downs of the ground also influences the stability of the human body, and this time also needs enough leg strength to regulate the body, to guarantee the stability of the body and the stability of firing. For the police, lower limb strength training is the most easily carried out a physical exercise. In his spare time can were squat training,, jump training and jogging training, do not require special facilities and equipment, these training can make a positive role to the leg strength.

\section{Endurance Training}

Endurance quality is also a physical fitness which related to the use of weapons. When the police is the process of law enforcement, no matter physical confrontation or long-distance to arrest the suspect will spend enormous physical ability. If there is no endurance quality as a support, when after a physical confrontation or raid, then the use of weapons for law enforcement, the body does not have enough ability to maintain stability of muscle strength and can not to control the stability of the body by adjusting the breathing, and then there is a greater impact to weapons use. Therefore, in the physical training related to the use of weapons, the endurance training is an important content. In general, flat support, push ups and other endurance events in the room can help improve the muscle endurance. If there are conditions in the stadium or gym, you can choose endurance break and equipment for a long time to repeat the exercise to improve muscle endurance. 


\section{Coordination Training}

Shooting is a very fine technical action. In the course of the shooting action, it tests the coordination ability of the inner of muscles and the muscles with each other, which is the special requirement of shooting (He, 2012). Especially in the actual process of law enforcement when after vigorous physical exercise and under the high mental load, this has a strong body and coordination ability to guarantee the height consistency of body action and consciousness, especially the small muscles of the fingers and wrist joints of fine coordination ability. Specifically, the coordination ability of finger and wrist can be improve by the practice of filliping, Pulling fingers and pushing palm. In addition, you can also attach importance to prepare the trigger training. In the process of the shooting sports, the index finger put force alone with appropriate intensity of overwhelming. Because the fingers and wrists are small muscle groups, it is easy to fatigue. In the course of the exercise should pay attention to the exercise load, prevent excessive damage due to excessive movement of the wrist and the sensitivity of the finger.

\section{Reaction Training}

Reaction ability is the most basic and core problem of weapon use. Over the years we have made the accuracy of the shooting as the main content of the study, and then derived from the various types of training methods. However, a variety of examples told us: no matter how exquisite shooting techniques, in the actual law enforcement process, if we do not have good response ability, no technology can be bought into play. For example in the sudden violence cases of assaulting a police officer, if law enforcement officers reaction ability is weak, it is likely that haven't pulled out a gun has been attacked by suspects witch resulting in no opportunity to use weapons. Therefore, in the actual process of law enforcement, all technology, tactics and even the relevant physical requirements about the use of weapons must regard the ability of response as a prerequisite (Guo, 2015). Specifically, the response of the law enforcement related to the police practice mainly includes: fast lateral movement, rapid turn, rapid retreat and other content.

\section{Conclusion}

The use of weapons by police is different from the sport of shooting. It words in a very complex environment and under the influence of many factors, so in addition to the stability of the psychological quality, it must also have a professional physical fitness as a guarantee. Muscular strength, muscular endurance, coordination ability of the finger and the body's respond ability influence the ability and effectiveness of the using of weapons of the police in the actual enforcement. Therefore, by selecting a few simple and practical training methods can make the police improve physical fitness which related to the using of weapon in their spare time and provide protection for the actual law enforcement.

\section{References}

Guo, W., 2015. Analysis on physical training of shooting. Science \& Technology of Stationery \& Sporting Goods, $15(6): 168$. He, Y., 2012. Analysis on the athletes physical ability training in shooting. Qinghai Sports Science and Technology, 50(2): 23-25. 